\title{
Aqueous Poly(arylacetylene) Dispersions
}

\author{
Johannes Huber and Stefan Mecking* \\ Chair of Chemical Materials Science, Department of Chemistry, University of Konstanz, \\ Universitätsstrasse 10, D-78457 Konstanz, Germany
}

Received June 18, 2010; Revised Manuscript Received September 6, 2010

\begin{abstract}
Aqueous poly(phenylacetylene) dispersions were obtained by catalytic polymerization in emulsion with a phosphine modified $\mathrm{Pd}(\mathrm{II})$ catalyst. A range of mono and bidentate phosphines were screened. $\mathrm{A} t \mathrm{Bu}_{2} \mathrm{P}\left(\mathrm{CH}_{2}\right)_{3} \mathrm{P} t \mathrm{Bu}_{2}$ modified catalyst exhibits very high rates up to $2 \times 10^{5} \mathrm{TO} \mathrm{h}{ }^{1}$ (TO moles of monomer converted per mole of metal present in the reaction mixture) in the preparation of colloidally stable poly (phenylacetylene) dispersions. Polymerization in miniemulsion afforded dispersions with up to $36 \mathrm{wt} \%$ solids content and average particle sizes of ca. $130 \mathrm{~nm}$. From microemulsions dispersions with ca. $25 \mathrm{~nm}$ particle size were obtained.
\end{abstract}

\section{Introduction}

Polymer dispersions have been studied intensely from a fundamental as well as applications oriented perspective. ${ }^{1,2}$ Thus, aqueous polymer dispersions are applied on a large scale in environmentally benign coatings and paints. By comparison to processing from solution in organic solvents, polymer dispersions can be beneficial for sensitive substrates and for the generation of nanocomposites. ${ }^{1,3}$ Moreover, otherwise unprocessable insoluble and intractable polymers can be processed from dispersions. ${ }^{4}$ Polymer dispersions are prepared most often by free-radical emulsion polymerization in a nonsolvent for the polymer, usually water. ${ }^{5,6}$ In recent years, controlled and nonradical polymerization routes to aqueous polymer dispersions have found increased interest. ${ }^{7}{ }^{13}$ Coordination polymerizations in emulsion can offer access to nanoparticles of polymers with microstructures inaccessible by other polymerization mechanisms. ${ }^{14}$ Also, in terms of the monomers polymerizable, coordination polymerization is largely complementary to free-radical polymerization.

The preparation and properties of substituted polyacetylenes have received considerable attention. ${ }^{15,16}$ Their molecular structure and physical properties, which comprise e.g. luminescence and liquid crystallinity, are influenced by the rigidity of the polyacetylene backbone which again is altered by the side-chain subsitutents. ${ }^{17}$ This is reflected in the polymer chain structure, e.g., in helicality.

Acetylene and substituted acetylenes can be polymerized by insertion polymerization or by metathesis polymerization. ${ }^{15,16}$ The water sensitivity of common catalysts based on titanium (insertion) and tungsten (metathesis) prohibits their use in aqueous systems. Insertion polymerization of substituted acetylenes in biphasic aqueous systems has been reported, most prominently with $\mathrm{Rh}$ catalysts. Catalyst productivities were moderate, with typically $10^{3}$ TO $(\mathrm{TO}=$ turnover, moles of substrate converted per mole of metal present in the reaction mixture). ${ }^{18,19}$ Polymerization of alkylacetylenes substituted with chiral substituents in aqueous surfactant solution containing dimethylformamide and SDS surfactant by a hydrophobic rhodium catalyst yielded dispersions of helical, optically active polymers. Productivities were limited, and a ratio of monomer:Rh of 50 was employed. Average particle sizes observed by TEM of $70100 \mathrm{~nm}$ are

\footnotetext{
*Corresponding author. E mail: stefan.mecking@uni konstanz.de.
}

relatively large given the large amount of surfactant employed, which exceeds the amount of monomer. The polymers formed have molecular weights around $M_{\mathrm{n}} 2 \times 10^{4} \mathrm{~g} \mathrm{~mol}{ }^{1}$, with narrow distributions, as determined by GPC in THF vs polystyrene standards. ${ }^{20}$ Metathesis cyclopolymerization of 1,6-heptadiynes, $\mathrm{HCCCH}_{2} \mathrm{C}\left(\mathrm{CO}_{2} \mathrm{R}\right)_{2} \mathrm{CH}_{2} \mathrm{CCH}$, with ruthenium alkylidenes bound to specific block copolymers has been reported to afford aqueous dispersions of the resulting polymers with productivities of $10^{2} \mathrm{TO}^{21}$ Because of the polymerization mechanism, by contrast to acyclic polymers from insertion polymerization of monofunctional substituted acetylenes, in these polymers every other backbone double bond is a member of a five-ring.

Cationic palladium complexes are well-known to copolymerize olefins with carbon monoxide by an insertion mechansim, ${ }^{22}$ also in aqueous systems, ${ }^{23}$ and they have been noted to polymerize substituted acetylenes in nonaqueous systems. ${ }^{24}$ On the other hand, mechanistic studies of acetylene insertion in cationic palladium complexes with bidentate nitrogen ligands $\left[\left(\mathrm{N}^{\wedge} \mathrm{N}\right) \mathrm{Pd}\left(\mathrm{CH}_{3}\right)(\mathrm{L})\right]^{+}$ revealed that after insertion of three acetylene molecules stable, unreactive $\pi$-allyl complexes were formed. ${ }^{25}$

We now give a first full account on the preparation of poly(arylacetylene) dispersions by polymerization in emulsion, utilizing very active phosphine-modified $\mathrm{Pd}(\mathrm{II})$ catalysts. ${ }^{26}$

\section{Results and Discussion}

Catalyst Screening. A range of mono- and bidentate phosphines varying in chelate ring size, steric bulk at the phosphorus atoms, and their electronic properties were screened for their ability to form an active $\mathrm{Pd}(\mathrm{II})$ catalyst for phenylacetylene polymerization (Tables 1 and 2). These studies were carried out in single phase homogeneous methanol solutions. By comparison to multiphase aqueous systems, this reduces the number of parameters potentially influencing the experiments such as droplet sizes, the surfactant concentration, or emulsion preparation procedure. In-situ catalyst systems $\mathrm{Pd}(\mathrm{OAc})_{2} /$ phosphine/methanesulfonic acid were employed. ${ }^{22}$ Concerning the formation of the active species, mechanistic studies on carbonylation reactions with such catalysts suggest that the role of the acid is protonation of the acetate ligands to acetic acid to generate a weakly coordinated species $\left(\mathrm{P}^{\wedge} \mathrm{P}\right) \mathrm{Pd}^{2+}{ }^{22}$ Such species can react with methanol to afford a metal hydride, ${ }^{27}$ which promotes polymerization. 
Table 1. Phenylacetylene Polymerization with Monophosphine Modified Catalysts ${ }^{a}$

\begin{tabular}{|c|c|c|c|c|}
\hline entry & phosphine & $\begin{array}{l}\text { phosphorus/ } \\
\text { palladium }^{b}\end{array}$ & $\begin{array}{l}\text { conversion/ } \\
\text { yield }(\%)\end{array}$ & $\mathrm{TON}^{c}$ \\
\hline \multirow[t]{3}{*}{11} & \multirow[t]{3}{*}{$\mathrm{HP} t \mathrm{Bu}_{2}$} & $6: 1$ & 0 & 0 \\
\hline & & $2: 1$ & 2 & 15 \\
\hline & & $1: 1$ & 1 & 13 \\
\hline \multirow[t]{2}{*}{12} & \multirow[t]{2}{*}{$\mathrm{MeP} t \mathrm{Bu}_{2}$} & $6: 1$ & 0 & 2 \\
\hline & & $2: 1$ & 1 & 10 \\
\hline \multirow[t]{2}{*}{13} & \multirow[t]{2}{*}{$\mathrm{P} n \mathrm{Bu}_{3}$} & $6: 1$ & 3 & 29 \\
\hline & & $1: 1$ & 3 & 26 \\
\hline \multirow[t]{3}{*}{14} & \multirow{3}{*}{$\mathrm{P}_{n} \mathrm{Oct}_{3}$} & $6: 1$ & 3 & 27 \\
\hline & & $2: 1$ & 3 & 30 \\
\hline & & $1: 1$ & 1 & 10 \\
\hline \multirow[t]{3}{*}{15} & \multirow[t]{3}{*}{$\mathrm{PPh}_{3}$} & $6: 1$ & 0 & 0 \\
\hline & & $2: 1$ & 7 & 63 \\
\hline & & $1: 1$ & 1 & 7 \\
\hline \multirow[t]{3}{*}{16} & \multirow[t]{3}{*}{$\mathrm{PCy}_{3}$} & $6: 1$ & 0 & 4 \\
\hline & & $2: 1$ & 1 & 5 \\
\hline & & $1: 1$ & 1 & 10 \\
\hline
\end{tabular}

${ }^{a}$ Polymerization at $25^{\circ} \mathrm{C}$ overnight. $50 \mu \mathrm{mol}$ of $\mathrm{Pd}(\mathrm{OAc})_{2}, 1$ drop of methanesulfonic acid, $5.0 \mathrm{~mL}$ of phenylacetylene $(46 \mathrm{mmol})$ in $25 \mathrm{~mL}$ of methanol. ${ }^{b}$ Molar ratio. ${ }^{c}$ TON turnover number moles of reacted monomer per mole of $\mathrm{Pd}$.

Table 2. Phenylacetylene Polymerization with Diphosphine Modified Catalysts $^{a}$

\begin{tabular}{|c|c|c|c|c|}
\hline entry & diphosphine & $\begin{array}{c}\text { phosphorus/ } \\
\text { palladium }^{b}\end{array}$ & $\begin{array}{l}\text { conversion } \\
\text { yield }(\%)\end{array}$ & $\mathrm{TON}^{c}$ \\
\hline \multirow[t]{2}{*}{21} & $t \mathrm{Bu}_{2} \mathrm{P}\left(\mathrm{CH}_{2}\right)_{3} \mathrm{P} t \mathrm{Bu}_{2}$ & $6: 1$ & 100 & $916^{d}$ \\
\hline & & $2: 1$ & 100 & $909^{d}$ \\
\hline \multirow{2}{*}{22} & $t \mathrm{Bu}_{2} \mathrm{P}\left(\mathrm{CH}_{2}\right)_{4} \mathrm{P} t \mathrm{Bu}_{2}$ & $6: 1$ & 7 & 65 \\
\hline & & $2: 1$ & 4 & 32 \\
\hline \multirow[t]{2}{*}{23} & $\mathrm{H}_{2} \mathrm{P}\left(\mathrm{CH}_{2}\right)_{3} \mathrm{PH}_{2}$ & $6: 1$ & 0 & 0 \\
\hline & & $2: 1$ & 0 & 0 \\
\hline \multirow[t]{2}{*}{24} & $\mathrm{Ph}_{2} \mathrm{PCH}_{2} \mathrm{PPh}_{2}$ & $6: 1$ & 0 & 0 \\
\hline & & $2: 1$ & 3 & 23 \\
\hline \multirow[t]{2}{*}{25} & $\mathrm{Ph}_{2} \mathrm{P}\left(\mathrm{CH}_{2}\right)_{2} \mathrm{PPh}_{2}$ & $6: 1$ & 0 & 0 \\
\hline & & $2: 1$ & 1 & 7 \\
\hline \multirow[t]{2}{*}{26} & $\mathrm{Ph}_{2} \mathrm{P}\left(\mathrm{CH}_{2}\right)_{3} \mathrm{PPh}_{2}$ & $6: 1$ & 0 & 0 \\
\hline & & $2: 1$ & 1 & 12 \\
\hline \multirow[t]{2}{*}{27} & $n \mathrm{Hex}_{2} \mathrm{P}\left(\mathrm{CH}_{2}\right)_{3} \mathrm{P} n \mathrm{Hex}_{2}$ & $6: 1$ & 0 & 0 \\
\hline & & $2: 1$ & 0 & 0 \\
\hline \multirow[t]{2}{*}{28} & $\mathrm{Cy}_{2} \mathrm{P}\left(\mathrm{CH}_{2}\right)_{3} \mathrm{PCy}_{2}$ & $6: 1$ & 0 & 2 \\
\hline & & $2: 1$ & 1 & 12 \\
\hline \multirow[t]{2}{*}{29} & $t \mathrm{Bu}_{2} \mathrm{PCH}_{2}\left(o \mathrm{C}_{6} \mathrm{H}_{4}\right) \mathrm{CH}_{2} \mathrm{P} t \mathrm{Bu}_{2}$ & $6: 1$ & 96 & $877^{d}$ \\
\hline & & $2: 1$ & 49 & 449 \\
\hline
\end{tabular}

${ }^{a}$ Polymerization at $25^{\circ} \mathrm{C}$ overnight. $50 \mu \mathrm{mol}$ of $\mathrm{Pd}(\mathrm{OAc})_{2}, 1$ drop of methanesulfonic acid, $5.0 \mathrm{~mL}$ of phenylacetylene $(46 \mathrm{mmol})$ in $25 \mathrm{~mL}$ of methanol. ${ }^{b}$ Molar ratio. ${ }^{c}$ TON turnover number moles of reacted monomer per mole of Pd. ${ }^{d}$ Limited by quantitative conversion.

A number of monophosphines were found to afford active catalysts of phenylacetylene, albeit these display moderate rates only (Table 1).

More active catalysts were obtained with appropriate diphosphines (Table 2). Various diphosphines with diarylalkyl or trialkyl substitution of the phosphorus donor with primary or secondary alkyl groups afforded catalysts with very low activities at the most (entries $2-3$ to $2-8$ ). Only diphosphines substituted with tert-butyl groups afforded very active catalysts for phenylacetylene polymerization (entries 2-1, 2-2, and 2-9). This is in agreement with Drent and Pello's previous notation that the catalyst system with ${ }^{t} \mathrm{Bu}_{2} \mathrm{P}\left(\mathrm{CH}_{2}\right)_{3} \mathrm{P}^{t} \mathrm{Bu}_{2}$ as a phosphine ligand is highly active for polymerization of acetylenes. ${ }^{24 a}$

The steric bulk of phosphane ligands can be described by Tolman's cone angle. The Tolman cone angles for $\mathrm{Ph}_{2} \mathrm{P}$ $\left(\mathrm{CH}_{2}\right)_{n} \mathrm{PPh}_{2}(n=1 \quad 3$; entries 46 in Table 2$)$ are $121^{\circ}, 125^{\circ}$, and $127^{\circ}$, respectively. For $\mathrm{Et}_{2} \mathrm{P}\left(\mathrm{CH}_{2}\right)_{2} \mathrm{PEt}_{2}$ and $\mathrm{Cy}_{2} \mathrm{P}-$ $\left(\mathrm{CH}_{2}\right)_{2} \mathrm{PCy}_{2}$, which should not differ substantially in steric bulk from the corresponding $\mathrm{C}_{3}$-bridged $n$-hexyl- and cyclohexyl-substituted diphosphines utilized in this work (entries 2-7 and 2-8), cone angles of $114^{\circ}$ and $142^{\circ}$, respectively, have been determined. The extreme steric bulk of the tert-butyl group is demonstrated by a cone angle of $182^{\circ}$ for $\mathrm{P} t \mathrm{Bu}_{3}$ vs $145^{\circ}$ for $\mathrm{PPh}_{3}$ and $170^{\circ}$ for $\mathrm{PCy}_{3}{ }^{28}$ From the comparison of the polymerization results with trialkyl-substituted diphosphines $\mathrm{R}_{2} \mathrm{P}\left(\mathrm{CH}_{2}\right)_{3} \mathrm{PR}_{2}(\mathrm{R}=n$-hexyl, $\mathrm{Cy}, t \mathrm{Bu})$ it appears that a high steric bulk of $\mathrm{R}$ is decisive for catalyst performance.

Diphosphines $t \mathrm{Bu}_{2} \mathrm{P} \quad \mathrm{X} \quad \mathrm{P} t \mathrm{Bu}_{2}\left(\mathrm{X}=\left(\mathrm{CH}_{2}\right)_{3}, \quad\left(\mathrm{CH}_{2}\right)_{4}\right.$,

$\left.\mathrm{CH}_{2}\left(o-\mathrm{C}_{6} \mathrm{H}_{4}\right) \mathrm{CH}_{2}\right)$ do not differ substantially in the steric bulk or electronic properties of the phosphorus donors, but in the chelate ring size formed upon bidentate, chelating coordination to a metal center. The phosphane with the propan1,3-diyl backbone should form more stable six-membered chelate complexes vs seven-membered chelates with the butan-1,4-diyl backbone. The large difference in catalytic properties observed with these two diphosphines suggests that a chelating bidentate coordination mode indeed occurs during catalysis. This is in agreement with the high catalyst activity also observed for the $o$-xylene- $\alpha, \alpha^{\prime}$-diyl backbone which should afford a seven-membered, but relatively stable, chelate due to the stiff backbone and spacial arrangement of the $\mathrm{P}$ donors.

Polymerization of phenylacetylene in the presence of $4 \mathrm{vol}$ $\%$ of water under conditions otherwise identical to entry 2-1 also resulted in complete monomer conversion, indicating that the catalyst is not particularly sensitive toward water.

An excess of phosphine ligand (P:Pd $=6: 1$ ) reduces catalyst activity in all cases except for the tert-butyl-substituted phosphines. Phosphines coordinate relatively strongly and in excess will block coordination sites for the substrates. The different behavior of the tert-butyl-substituted phosphines observed may be due to coordination being hindered to a certain extent by the very bulky substitution of the phosphorus donors. Competitive protonation of the electron-rich phosphine by the acidic catalyst component may also play a role. ${ }^{29}$

Poly(phenylacetylene) Dispersions. A high degree of dispersion of the reaction mixture is a prerequisite for the preparation of submicrometer particle dispersions. In the case of catalytic polymerization with lipophilic catalyst precursors, this can be achieved by dispersing the catalyst precursor as a solution in the organic phase of an aqueous mini- or microemulsion. ${ }^{30}$ The organic phase can be a small amount of added organic solvent, e.g., toluene, or in reactions of monomers which are liquid under reaction conditions also the neat monomer. In the latter case, care must be taken that the polymerization only starts after the emulsification procedure. Otherwise, large colloidally unstable particles will form. A mixture of an aqueous SDS solution with a solution of $\mathrm{Pd}(\mathrm{OAc})_{2}$ and $t \mathrm{Bu}_{2} \mathrm{P}\left(\mathrm{CH}_{2}\right)_{3} \mathrm{P} t \mathrm{Bu}_{2}$ in phenylacetylene was ultrasonicated to form a miniemulsion. Subsequent addition of a drop of methanesulfonic acid triggered the polymerization, as evidenced by a color change of the emulsion to deep yellow, and the onset of heat evolution in experiments with higher monomer volumes and catalyst loadings (Table 3 ).

Yellow poly(phenylacetylene) dispersions, with a slight orange touch at higher solids contents, are formed. Even at a low catalyst loading of $0.4 \mu \mathrm{mol}$ (entry 3-6) complete monomer conversion was observed. This corresponds to a productivity of $2 \times 10^{5} \mathrm{TO}$ in a $1 \mathrm{~h}$ polymerization experiment. Polymer molecular weights are chain transfer controlled (entries 3-2 to 3-6). Dispersions of up to $36 \mathrm{wt} \%$ polymer solids content were prepared. Volume average particle sizes are $110160 \mathrm{~nm}$, as determined by DLS, depending on the monomer volume portion. The dispersions are colloidally 
stable for more than a year, as evidenced by no significant change in particle size occurring. TEM images demonstrate the poly(phenylacetylene) particles to be spherical (Figure 1).

The polymerization of 3-methoxy-4- $n$-hexyloxyphenylacetylene (MHPA), 1-naphtylacetylene (NA), and 9-anthracenylacetylene (AA) was studied (Table 4). Polymerizations were carried out at $60^{\circ} \mathrm{C}$. At this temperature all monomers are liquid. The reactivity of the catalyst system employed toward these monomers appears to be lower by comparison to phenylacetylene (PA). While the latter was converted completely at a catalyst loading of $0.2 \mu \mathrm{mol}$ under the conditions studied (entry 4-1), MHPA and NA were only converted to about $15 \%$. However, complete conversion of these monomers was achieved at a catalyst loading of $2 \mu \mathrm{mol}$,

Table 3. Polymerization of Phenylacetylene in Monomer Miniemulsions $^{a}$

\begin{tabular}{|c|c|c|c|c|c|c|}
\hline entry & $\begin{array}{l}n(\mathrm{Pd}) \\
(\mu \mathrm{mol})\end{array}$ & $\begin{array}{l}\text { polymer solids } \\
\text { content }(\%)\end{array}$ & $\begin{array}{c}\text { particle } \\
\text { size }^{b}(\mathrm{~nm})\end{array}$ & PDI & $\begin{array}{c}\text { molecular } \\
\text { weight }^{c}\left(M_{\mathrm{w}}\right)\end{array}$ & $\begin{array}{l}M_{\mathrm{w}} / \\
M_{\mathrm{n}}{ }^{c}\end{array}$ \\
\hline 31 & 30 & 36 & 142 & 0.18 & & \\
\hline 32 & 20 & 20 & 160 & 0.13 & $4.2 \times 10^{4}$ & 4.2 \\
\hline 33 & 4.0 & 19 & 137 & 0.12 & $3.5 \times 10^{4}$ & 3.8 \\
\hline 34 & 2.0 & 18 & 117 & 0.12 & $3.9 \times 10^{4}$ & 4.3 \\
\hline 35 & 1.0 & 17 & 114 & 0.14 & $3.5 \times 10^{4}$ & 4.3 \\
\hline 36 & 0.4 & 17 & 112 & 0.18 & $3.1 \times 10^{4}$ & 4.6 \\
\hline
\end{tabular}

${ }^{a}$ Polymerization at room temperature, $1 \mathrm{~h}$ polymerization time. $\mathrm{Pd}(\mathrm{OAc})_{2} / t \mathrm{Bu}_{2} \mathrm{P}\left(\mathrm{CH}_{2}\right)_{3} \mathrm{P} t \mathrm{Bu}_{2}$ 1:3 molar ratio. Total volume of reaction mixture: $50 \mathrm{~mL}$; ca. $9 \mathrm{~g}$ of phenylacetylene (entry $31: 18 \mathrm{~g}$ ); $1 \%$ aque ous SDS solution. ${ }^{b}$ Volume average particle size determined by DLS. ${ }^{c}$ Molecular weights determined by GPC in THF vs linear polystyrene standards.

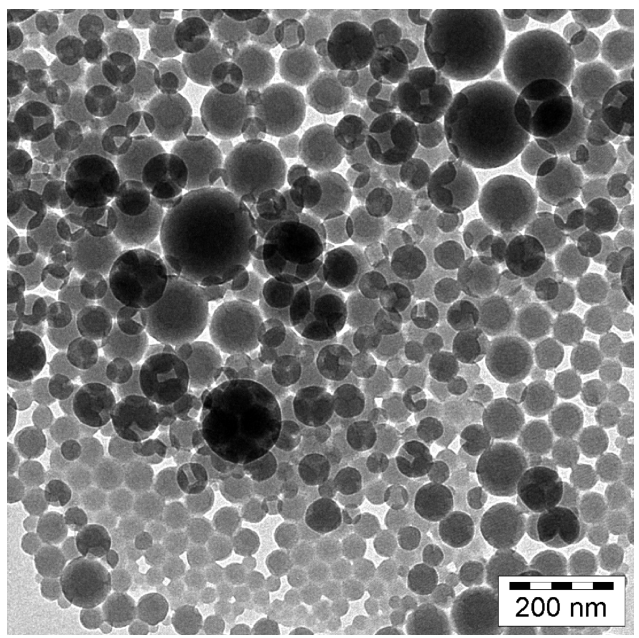

Figure 1. TEM image of poly(phenylacetylene) particles from poly merization in miniemulsion (entry 3 4; number average diameter deter mined: $57 \mathrm{~nm}$ ). corresponding to a catalyst productivity of $5.4 \times 10^{3} \mathrm{TO}$ (MHPA) and $8.2 \times 10^{4}$ TO (NA). Whereas the particle size distribution of poly(phenylacetylene) dispersions was monomodal (131 nm volume average size), the particle size distributions of the poly-MHPA and poly-NA dispersions were bimodal, as determined by the DLS method employed, when undiluted monomers were used (entries 4-2 to 4-5). This is due to the higher viscosity of the monomers MHPA and NA, which hampers the generation of uniform small droplets in the miniemulsification step, as concluded from polymerizations of emulsions of MHPA and NA monomers diluted with hexane, which resulted in monomodal dispersions (entries 4-7 and 4-8). For the poly-MHPA from entry 4-3, a molecular weight of $M_{\mathrm{w}}=1.2 \times 10^{5}\left(M_{\mathrm{w}} / M_{\mathrm{n}} 3.6\right)$ was determined. ${ }^{31}$

Microemulsions represent very highly disperse biphasic systems. Free-radical polymerization in microemulsions ${ }^{32}$ and also catalytic polymerizations ${ }^{33}$ can afford polymer particles with sizes as low as $510 \mathrm{~nm}$. A microemulsion is a thermodynamically stable mixture of at least two immiscible liquids and a surfactant, which exists in a certain range of compositions. Frequently, an alcohol is added to achieve the microemulsion regime. Microemulsions can possess globular phase structures (oil-in-water, o/w, or water-in oil, $\mathrm{w} / \mathrm{o}$ ) as well as lamellar or irregular bicontinuous structures. ${ }^{32}$ Spontaneous formation is an indicator for the existence of a microemulsion.

For the system studied, a suitable composition which is in the microemulsion regime was found to be phenylacetylene: SDS:pentanol:water in a mass ratio of 6:8:4:82. Gentle stirring overnight afforded a transparent microemulsion. Other than miniemulsions, microemulsions are highly dynamic. In order to prevent premature polymerization, the catalyst and monomer must be microemulsified separately. After mixing of the two microemulsions, the oil phases containing the catalyst solution and the monomer can exchange by continuous merging and separation. The equilibrated monomer and catalyst microemulsions were mixed, and polymerization was started by addition of methanesulfonic acid. Even at a low catalyst loading of $0.4 \mu \mathrm{mol}$ complete monomer conversion was observed, corresponding to a catalyst productivity of $7 \times 10^{4} \mathrm{TO}$ in a $1 \mathrm{~h}$ experiment. Transparent yellow dispersions with solids contents of $\sim 6 \%$ were formed (Table 5 ). Note that the solids content is limited by the necessity of the initial reaction mixture being in the microemulsion regime. Volume average particle sizes of $2529 \mathrm{~nm}$ were determined by DLS (Figure 2 and Table 5). Particle sizes are largely independent of the catalyst concentration. TEM analysis of the particles (Figure 3 ) is in agreement with the DLS studies.

As in the polymerization in miniemulsions, molecular weights are controlled by chain transfer (entries 5-1 to 5-5).

"Doped" bulk polyacetylene possesses electrical conductivities of $10^{2} 10^{5} \mathrm{~S} \mathrm{~cm}{ }^{134}$ By comparison to the parent

Table 4. Polymerization Results of Various Arylacetylenes in Aqueous Emulsion ${ }^{a}$

\begin{tabular}{|c|c|c|c|c|c|c|}
\hline entry & monomer & catalyst ( $\mu \mathrm{mol})$ & polymer solids content & particle size ${ }^{b}$ & monomer conversion & color of the latex \\
\hline 41 & PA & 0.2 & $16.5 \%$ & $131 \mathrm{~nm}$ & quantitative & yellow \\
\hline 42 & MHPA & 0.2 & $2.4 \%$ & $100 / 654 \mathrm{~nm}$ & $15 \%$ & yellow \\
\hline 43 & MHPA & 2.0 & $16.4 \%$ & $217 \mathrm{~nm} / 1.1 \mu \mathrm{m}$ & quantitative & yellow \\
\hline 44 & NA & 0.2 & $2.2 \%$ & $122 \mathrm{~nm} / 1.0 \mu \mathrm{m}$ & $13 \%$ & dark violet \\
\hline 45 & NA & 2.0 & $16.4 \%$ & $61 \mathrm{~nm} / 1.1 \mu \mathrm{m}$ & quantitative & dark violet \\
\hline 46 & $\mathrm{AA}$ & 2.0 & (coagulated) & $615 \mathrm{~nm} / 84 \mathrm{~nm}$ & $-c$ & dark brown \\
\hline $47^{d}$ & NA & 2.0 & $3.0 \%$ & $36 \mathrm{~nm}$ & quantitative & dark violet \\
\hline $48^{e}$ & MHPA & 2.0 & $6.6 \%$ & $119 \mathrm{~nm}$ & quantitative & yellow \\
\hline
\end{tabular}

${ }^{a}$ Polymerization temperature $60^{\circ} \mathrm{C}$; reaction time $1 \mathrm{~h} ; \mathrm{Pd}(\mathrm{OAc})_{2} / t \mathrm{Bu}_{2} \mathrm{P}\left(\mathrm{CH}_{2}\right)_{3} \mathrm{P} t \mathrm{Bu}_{2} \quad 1: 3$; total volume: $15 \mathrm{~mL} ; 2.5 \mathrm{~g}$ of monomer, $150 \mathrm{mg}$ of SDS; 10 min ultrasonication. ${ }^{b}$ Volume average particle size determined by DLS; bimodal distributions determined with the method employed for samples 42 to 45 . ${ }^{c}$ Coagulated during polymerization, conversion could not be determined due to inclusion of monomer into the insoluble polymer. ${ }^{d} 0.5 \mathrm{~g}$ of monomer in $2.5 \mathrm{~g}$ of hexane. ${ }^{e} 1.0 \mathrm{~g}$ monomer in $2 \mathrm{~g}$ of hexane. 
Table 5. Polymerizations of Phenylacetylene in Aqueous Monomer Microemulsions $^{a}$

\begin{tabular}{cccccc}
\hline entry & $\begin{array}{c}n(\mathrm{Pd}) \\
(\mu \mathrm{mol})\end{array}$ & $\begin{array}{c}\text { polymer solids } \\
\text { content }(\%)\end{array}$ & $\begin{array}{c}\text { particle size } \\
(\mathrm{nm})\end{array}$ & $\begin{array}{c}\text { molecular } \\
\text { weight }^{c}\left(M_{\mathrm{w}}\right)\end{array}$ & $M_{\mathrm{w}} / M_{\mathrm{n}}{ }^{c}$ \\
\hline $5 \mathrm{5}$ & 10 & 5.9 & 25 & $5.5 \times 10^{3}$ & 2.7 \\
$5 \mathrm{5}$ & 5 & 6.0 & 27 & $3.4 \times 10^{4}$ & 5.1 \\
53 & 2.5 & 6.2 & 27 & $3.7 \times 10^{4}$ & 4.5 \\
$5 \mathrm{5}$ & 1.25 & 6.0 & 29 & $2.6 \times 10^{4}$ & 5.7 \\
55 & 0.4 & 5.6 & 29 & $3.4 \times 10^{4}$ & 5.3
\end{tabular}

${ }^{a}$ Polymerization temperature $25{ }^{\circ} \mathrm{C}$; reaction time $1 \mathrm{~h}$; $\mathrm{Pd}(\mathrm{OAc})_{2} /$ $t \mathrm{Bu}_{2} \mathrm{P}\left(\mathrm{CH}_{2}\right)_{3} \mathrm{P} t \mathrm{Bu}_{2} \quad 1: 3$; total volume: $50 \mathrm{~mL} ; 6.0 \mathrm{wt} \%$ phenylacetylene, $8.0 \mathrm{wt} \% \mathrm{SDS}, 4.0 \mathrm{wt} \%$ pentanol. ${ }^{b}$ Volume average particle size determined by DLS. ${ }^{c}$ Determined by GPC in THF vs linear polystyrene standards.

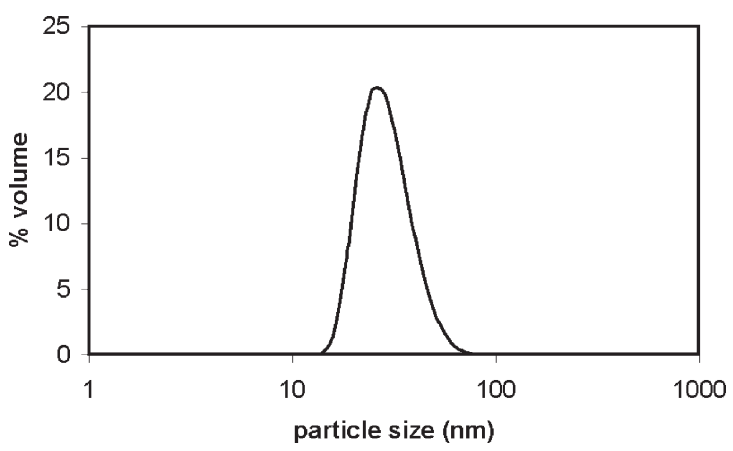

Figure 2. DLS trace of a poly(phenylacetylene) dispersion from poly merization in microemulsion (entry 53 ).

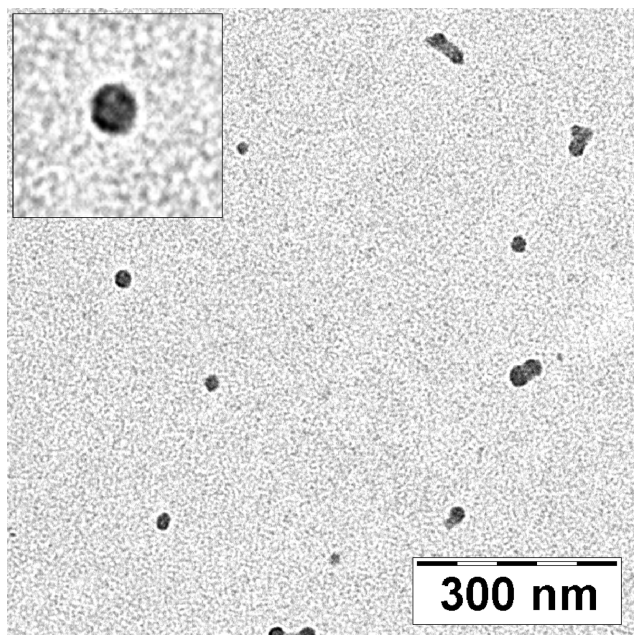

Figure 3. TEM of phenylacetylene particles from polymerization in microemulsion (entry 53 ).

polyacetylene, the introduction of substituents on the main chain strongly reduces conductivity. Conductivities around $10{ }^{5} \mathrm{~S} \mathrm{~cm}{ }^{1}$ were reported for poly(phenylacetylene) treated with iodine. ${ }^{35}$ Also for the polyphenyacetylenes prepared in this work, conductivities of $3 \times 10{ }^{5} \mathrm{~S} \mathrm{~cm}{ }^{1}$ were observed on iodine-"doped" compressed pellets. As an illustration of the patterning of these reactive submicrometer particles, the dispersion were printed with an inkjet printer to obtain photoquality resolution yellow images. Exposure to bromine converts these to black-and-white style pictures due to the unsaturated nature of the polymer (cf. Supporting Information).

\section{Summary and Conclusions}

Cationic palladium(II) complexes with a bidentate diphosphine ligand substituted with very bulky tert-butyl substituents are highly active for catalytic polymerization of phenylacetylene in aqueous emulsions. Catalyst productivities of $2 \times 10^{5} \mathrm{~mol}$ turnovers were observed. Colloidally stable poly(phenylacetylene) dispersions with polymer solids contents of up to $36 \mathrm{wt} \%$ were obtained. With a microemulsion technique very small particles of $<30 \mathrm{~nm}$ size are accessible. Substituted phenylacetylenes were also amenable to polymerization to afford stable dispersions with substantial solids contents.

\section{Experimental Section}

General Methods and Materials. All manipulations involving phosphines were carried out under an inert atmosphere in a drybox or by standard Schlenk techniques. THF was distilled from sodium. Demineralized water was degassed by distillation under argon. NMR spectra were recorded on a Varian Unity INOVA 400 or on a Bruker AC 250 spectrometer. ${ }^{1} \mathrm{H}$ and ${ }^{13} \mathrm{C}$ NMR chemical shifts were referred to the solvent signal. Size exclusion chromatography was carried out on a polymer labo ratories PL 50 instrument equipped with two PLgel $5 \mu \mathrm{m}$ MIXED C columns columns in THF in THF at $40{ }^{\circ} \mathrm{C}$ with an RI detector. Data are referenced to linear polystyrene stan dards. Dynamic light scattering (DLS) on diluted dispersion samples was performed on a Malvern Nano ZS ZEN 3600 parti cle sizer $\left(173^{\circ}\right.$ backscattering). The autocorrelation function was analyzed using the Malvern dispersion technology software 5.10 algorithm to obtain volume and number weighted particle size distributions and polydispersity indices (PDI). TEM images were obtained on a Libra 120 instrument (acceleration voltage $120 \mathrm{kV}$ ). Conductivities were determined on compressed pellets by the four point method. Phenylacetylene (98\%), tricyclohexyl phosphane, tri $n$ butylphosphine (95\%), and 1,4 dichlorobutane $(99 \%)$ were purchased from Acros, $\mathrm{LiAlH}_{4}$ was purchased from Merck, and 1 hexene $(97 \%)$ was purchased from Aldrich. SDS $(\geq 96 \%$ ) was purchased from Fluka. Dibromonomethyltriphenyl phosphonium bromide, ${ }^{36} 4$ (hexyloxy) 3 methoxybenzaldehyde, ${ }^{37}$ 1,3 bis(di tert butylphosphino)propane, ${ }^{38}$ and 1,3 bis(di $n$ hexyl phosphino)propane ${ }^{23 \mathrm{~d}}$ were prepared according to published procedures.

Synthesis of 3-Methoxy-4-n-hexyloxyphenylacetylene (MHPA). Under an argon atmosphere, $47.95 \mathrm{~g}$ of dibromonomethyltri phenylphosphonium bromide $(93.1 \mathrm{mmol})$ and $9.92 \mathrm{~g}$ of tBuOK (88.4 mmol) were dissolved in $450 \mathrm{~mL}$ of dry THF. The solution was cooled to $80^{\circ} \mathrm{C}$ and stirred for several minutes. $11.0 \mathrm{~g}$ of 4 (hexyloxy) 3 methoxybenzaldehyde $(46.6 \mathrm{mmol})$ was added in one batch, and the solution was warmed to room tempera ture. After $10 \mathrm{~min}, 26.1 \mathrm{~g}$ of $\mathrm{tBuOK}$ was added in one batch. The solution was quenched with saturated brine $(300 \mathrm{~mL})$ and extracted with ether. The combined organic layers were dried over $\mathrm{MgSO}_{4}$, and the solvent was evaporated. The residue was extracted with ether, the extract was filtered through diatom aceous earth, and the solvent was evaporated. The product was purified by column chromatography (PE:ethyl acetate 1:1) to obtain $10.1 \mathrm{~g}$ of 4 ethynyl 1 (hexyloxy) 2 methoxybenzene (93\%). ${ }^{1} \mathrm{H}$ NMR (400 MHz, $\left.\mathrm{CDCl}_{3}\right): \delta 7.07$ (dd, $J$ 1.9, 8.3, $1 \mathrm{H}), 6.98(\mathrm{~d}, J \quad 1.9,1 \mathrm{H}), 6.79(\mathrm{~d}, J \quad 8.3,1 \mathrm{H}), 4.00(\mathrm{t}, J \quad 6.9$, $2 \mathrm{H}), 3.85(\mathrm{~s}, 3 \mathrm{H}), 3.00(\mathrm{~s}, 1 \mathrm{H}), 1.891 .77(\mathrm{~m}, 2 \mathrm{H}), 1.44(\mathrm{dq}, J$ $7.1,9.6,2 \mathrm{H}), 1.33(\mathrm{td}, J \quad 3.6,7.2,4 \mathrm{H}), 0.93 \quad 0.85(\mathrm{~m}, 3 \mathrm{H}) .{ }^{13} \mathrm{C}$ NMR $\left(101 \mathrm{MHz}, \mathrm{CDCl}_{3}\right): \delta 149.68,149.10,125.63,115.29$, $114.16,112.52,84.07,75.73,69.15,56.14,31.74,29.20,25.78$, $22.75,14.19$.

Synthesis of 1-Naphtylacetylene (NA). Under an argon atmo sphere, $65.94 \mathrm{~g}$ of dibromonomethyltriphenylphosphonium bromide $(128.1 \mathrm{mmol})$ and $13.6 \mathrm{~g}$ of tBuOK $(121 \mathrm{mmol})$ were dissolved in $600 \mathrm{~mL}$ of dry THF. The solution was cooled to $80^{\circ} \mathrm{C}$ and stirred for several minutes. $10.0 \mathrm{~g}$ of 1 naphthaldehyde $(64.0 \mathrm{mmol})$ was added at once, and the solution was warmed to room temperature. After $10 \mathrm{~min}, 35.9 \mathrm{~g}$ of $\mathrm{tBuOK}$ was added at once. The solution was quenched with saturated brine $(500 \mathrm{~mL})$ and extracted with ether. The combined organic layers were dried over $\mathrm{MgSO}_{4}$, and the solvent was evaporated. The residue was 
extracted with ether and filtered through diatomaceous earth, and the filtrate was evaporated. The product was purified by column chromatography (PE:ethyl acetate $1: 1$ ) to obtain $6.81 \mathrm{~g}$ of 4 ethinyl 1 (hexyloxy) 2 methoxybenzene (70\%). ${ }^{1} \mathrm{H}$ NMR $\left(400 \mathrm{MHz}, \mathrm{CDCl}_{3}\right): \delta 8.42(\mathrm{~d}, J \quad 8.4,1 \mathrm{H}), 7.88(\mathrm{~d}, J \quad 8.2,2 \mathrm{H})$, 7.79 (dd, $J \quad 1.0,7.1,1 \mathrm{H}), 7.59$ (dddd, $J \quad 1.3,6.9,8.2,26.5,2 \mathrm{H})$, $7.46(\mathrm{dd}, J \quad 7.2,8.3,1 \mathrm{H}), 3.52(\mathrm{~s}, 1 \mathrm{H}) .{ }^{13} \mathrm{C}$ NMR $(101 \mathrm{MHz}$, $\left.\mathrm{CDCl}_{3}\right): \delta 133.70,133.27,131.42,129.47,128.48,127.14,126.67$, $126.23,125.28,119.96,82.19,81.96$.

Synthesis of 1,4-Bis(di-tert-butylphosphino)butane. In a $100 \mathrm{~mL}$ Schlenk tube, $5.0 \mathrm{~g}$ of di tert butylphosphine $(34 \mathrm{mmol})$ was dissolved in $30 \mathrm{~mL}$ of $\mathrm{Et}_{2} \mathrm{O}$, and the mixture was cooled to $0{ }^{\circ} \mathrm{C}$ in an ice bath. Within $10 \mathrm{~min}, 23.90 \mathrm{~mL}$ of tBuLi (1.5 M solution in hexane, $35.9 \mathrm{mmol}$ ) was added dropwise. $2.246 \mathrm{~g}$ of 1,4 dichlorobutane $(17.68 \mathrm{mmol})$ was added in a single batch, upon which the solution became pale yellow. The solution was stirred for $20 \mathrm{~min}$ at $0{ }^{\circ} \mathrm{C}$ and another hour at room temperature. The solvent was removed, and $10 \mathrm{~mL}$ of hexane followed by $10 \mathrm{~mL}$ of water was added. The organic layer was extracted three times with $10 \mathrm{~mL}$ of hexane each. From the combined organic layers the solvent was evaporated, and the crude product was purified by Kugelrohr distillation at $130{ }^{\circ} \mathrm{C}(0.2 \mathrm{mbar})$ to obtain $4.05 \mathrm{~g}$ of 1,4 bis(di tert butylphosphino)butane $(85 \%)$. ${ }^{1} \mathrm{H}$ NMR (400 MHz, $\left.\mathrm{C}_{6} \mathrm{D}_{6}, 25^{\circ} \mathrm{C}\right): \delta / \mathrm{ppm} \quad 1.72(\mathrm{~m}, 4 \mathrm{H}), 1,33$ $(\mathrm{m}, 4 \mathrm{H}), 1.03\left(\mathrm{~d}, 36 \mathrm{H},{ }^{3} J_{\mathrm{HP}} \quad 10,8 \mathrm{~Hz}\right) .{ }^{31} \mathrm{P}$ NMR $(162 \mathrm{MHz})$ : $\delta 29.0$.

Preparation of Catalyst Solution (Example). A solution of $33.7 \mathrm{mg}(150 \mu \mathrm{mol})$ of $\mathrm{Pd}(\mathrm{OAc})_{2}$ in $5 \mathrm{~mL}$ of acetonitrile and a solution of $149.5 \mathrm{mg}(450 \mu \mathrm{mol})$ of 1,3 bis(di tert butylphos phino)propane in $5 \mathrm{~mL}$ of ethanol were mixed, and the solvent was evaporated in vacuo. The residue was dissolved in a mixture of $0.2 \mathrm{~mL}$ of ethanol and $4.8 \mathrm{~mL}$ of hexane to afford a catalyst solution with a concentration of $30 \mu \mathrm{mol} \mathrm{Pd} / \mathrm{mL}$.

Miniemulsion Polymerization Procedure. In a $100 \mathrm{~mL}$ round bottom Schlenk flask closed with a septum, an aqueous solution of $0.5 \mathrm{~g}$ of SDS in $39 \mathrm{~g}$ of water was topped with a layer of $10 \mathrm{~mL}$ of phenylacetylene. To this layer $1.0 \mathrm{~mL}$ of catalyst solution $(30 \mu \mathrm{mol})$ was added. The mixture was ultrasonicated for $2 \mathrm{~min}$ (Bandelin HD 2200 with a KE76 tip, operated at $120 \mathrm{~W}$ ), followed by addition of one drop of methanesulfonic acid while stirring. The initially pale yellow emulsion turned to an intense yellow while the temperature increased significantly. After $1 \mathrm{~h}$ of polymerization an intensely yellow dispersion was obtained.

For analysis, $10 \mathrm{~mL}$ of the dispersion was precipitated in $100 \mathrm{~mL}$ of methanol, followed by filtration through a nylon filter $(0.45 \mu \mathrm{m}$ pore size $)$. The polymer was washed with methanol and dried at room temperature.

Microemulsion Polymerization Procedure. In a $100 \mathrm{~mL}$ round bottom Schlenk flask closed with a septum, a mixture of $3.0 \mathrm{~g}$ of phenylacetylene, $4.0 \mathrm{~g}$ of SDS, $4.0 \mathrm{~g}$ of pentanol, and $44.5 \mathrm{~g}$ of water was stirred overnight to afford a clear microemulsion. In a separate Schlenk flask, $7.5 \mathrm{~mL}$ of water, $1.0 \mathrm{~g}$ of SDS, and $0.5 \mathrm{~g}$ of pentanol were mixed with $1.0 \mathrm{~mL}$ of catalyst solution $(20 \mu \mathrm{mol} / \mathrm{mL})$ and stirred for $5 \mathrm{~min}$ to afford a clear microemul sion. For polymerization, $1.25 \mathrm{~mL}$ of catalyst microemulsion was transferred to the monomer microemulsion. After $1 \mathrm{~min}$ of stirring, one drop of methanesulfonic acid was added to the mixture. After $1 \mathrm{~h}$ of polymerization, an intensely orange colored latex was obtained.

Acknowledgment. Financial support by the DFG (Me1388/ 7 1) is gratefully acknowledged. We thank Marina Krumova for TEM analyses and Lars Bolk for GPC analyses. S.M. is indebted to the Fonds der Chemischen Industrie and to the Hermann Schnell Foundation.

Supporting Information Available: Images of inkjet print outs with the dispersions. This material is available free of charge via the Internet at http://pubs.acs.org.

\section{References and Notes}

(1) (a) Urban, D.; Takamura, K. Polymer Dispersions and Their Industrial Applications; Wiley-VCH: Weinheim, 2002. (b) van Herk, A. M. Chemistry and Technology of Emulsion Polymerisation; Blackwell Publishing: Oxford, 2005. (c) Fitch, R. M. Polymer Col loids; Academic Press: San Diego, 1997. (d) Lovell, P. A.; El-Aasser, M. S. Emulsion Polymerization and Emulsion Polymers; Wiley: Chichester, 1997.

(2) Pecher, J.; Mecking, S. Chem. Rev. 2010, in press (doi 10.1021/ cr100132y)

(3) (a) Antonietti, M.; Landfester, K. Prog. Polym. Sci. 2002, 27, 689 757. (b) Kietzke, T.; Neher, D.; Landfester, K.; Montenegro, R.; Guntner, R.; Scherf, U. Nature Mater. 2003, 2, 408 412. (c) Bourgeat-Lami, E. In Encyclopedia of Nanoscience and Nanotechnology; Nalwa, H. S., Ed.; American Scientific Publishers: Stevenson Ranch, CA, 2004; Vol. 8, pp 305-332. (d) Wiese, H.; Xue, Z.; Leuninger, J. Chem. Unserer Zeit 2005, 39, 65 66. (e) Monteil, V.; Stumbaum, J.; Thomann, R.; Mecking, S. Macromolecules 2006, 39, 2056 2062. (f) Balmer, J. A.; Schmid, A.; Armes, S. P. J. Mater. Chem. 2008, 18, 57225730.

(4) Huber, J.; Mecking, S. Angew. Chem., Int. Ed. 2006, 45, 63146317.

(5) Asua, J. M. Prog. Polym. Sci. 2002, 27, 12831346.

(6) Zetterlund, B.; Kagawa, Y.; Okubo, M. Chem. Rev. 2008, 108, 37473794

(7) (a) Lowe, A. B.; McCormick, C. L. Aust. J. Chem. 2002, 55, 367 379. (b) Prescott, S. W.; Ballard, M. J.; Rizzardo, E.; Gilbert, R. G. Aust. J. Chem. 2002, 55, 415 424. (c) Cunningham, M. F. Prog. Polym. Sci. 2002, 27, 1039 1067. (d) Mecking, S.; Claverie, J. In Late Transition Metal Polymerization Catalysis; Rieger, B., Baugh, L. S., Kacker, S., Striegler, S., Eds.; Wiley-VCH: Weinheim, 2003; pp 231-278. (e) Charleux, B. In Macromolecular Engineering; Matyjaszewski, K., Gnanou, Y., Leibler, L., Eds.; Wiley: New York, 2007; Vol. 1, pp 605-642.

(8) (a) Landfester, K. Annu. Rev. Mater. Res. 2006, 36, 231 79. (b) Dieterich, D.; Uhlig, K. In Ullmann's Encylopedia of Industrial Chemistry, 6th ed.; Wiley-VCH: Weinheim, 2003; Vol. 28, pp 667-722.

(9) Quémener, D.; Héroguez, V.; Gnanou, Y. Macromolecules 2005, 38, 79777982

(10) Quémener, D.; Bousquet, A.; Héroguez, V.; Gnanou, Y. Macro molecules 2006, 39, 55895591.

(11) Airaud, C.; Héroguez, V.; Gnanou, Y. Macromolecules 2008, 41, 30153022

(12) Lynn, D. M.; Mohr, B.; Grubbs, R. H.; Henling, L. M.; Day, M. W. J. Am. Chem. Soc. 2000, 122, 66016609.

(13) Wache, S. J. Organomet. Chem. 1995, 495, 235240

(14) (a) Mecking, S. Colloid Polym. Sci. 2007, 285, 605 619. (b) Claverie, J. P.; Soula, R. Prog. Polym. Sci. 2003, 28, 619 662. (c) Mecking, S.; Held, A.; Bauers, F. M. Angew. Chem., Int. Ed. 2002, 41, 544561.

(15) (a) Furlani, A.; Napoletano, C.; Russo, M. V.; Feast, W. J. Polym. Bull. 1986, 16, 311 317. (b) Trumbo, D. L.; Marvel, C. S. J. Polym. Sci., Part A 1987, 25, 1027 1034. (c) Masuda, T.; Mishima, K.; Fujimori, J.; Nishida, M.; Muramatsu, H.; Higashimura, T. Macro molecules 1992, 25, 1401 1404. (d) Schrock, R. R.; Luo, S.; Zanetti, N. C.; Fox, H. H. Organometallics 1994, 13, 3396 3398. (e) Kishimoto, Y.; Eckerle, P.; Miyatake, T.; Kainosho, M.; Ono, A.; Ikariya, T.; Noyori, R. J. Am. Chem. Soc. 1999, 121, 12035 12044. (f) Hori, H.; Six, C.; Leitner, W. Macromolecules 1999, 32, 31783182.

(16) (a) Ginsburg, E. J.; Gorman, C. B.; Grubbs, R. H. In Modern Acetylene Chemistry; Stang, P. J., Diederich, F., Eds.; VCH: Weinheim, 1995; pp 353-83. (b) Belov, D. G.; Efimov, O. N.; Belov, G. P. Plast. Eng. 1998, 45, 297-330. (c) Buchmeiser, M. R. Adv. Polym. Sci. 2006, 197, 137171.

(17) (a) Neher, D.; Kaltbeitzel, A.; Wolf, A.; Bubeck, C.; Wegner, G. J. Phys. D: Appl. Phys. 1991, 24, 1193 1202. (b) Sakurai, S.-I.; Kuroyanagi, K.; Morino, K.; Kunitake, M.; Yashima, E. Macromole cules 2003, 36, 9670 9674. (c) Lam, J. W. Y.; Tang, B. Z. Acc. Chem. Res. 2005, 38,745 754. (d) Maeda, K.; Matsushita, Y.; Ezaka, M.; Yashima, E. Chem. Commun. 2005, 4152 4154. (e) Fukushima, T.; Takachi, K.; Tsuchihara, K. Macromolecules 2006, 39, 31033105.

(18) (a) Amer, I.; Schumann, H.; Ravindar, V.; Baidossi, W.; Goren, N.; Blum, J. J. Mol. Catal. 1993, 85, 163 171. (b) Yashima, E.; Matsushima, T.; Okamoto, Y. J. Am. Chem. Soc. 1997, 119, 6345 6359. (c) Tang, B. Z.; Poon, W. H.; Leung, S. M.; Leung, W. H.; Peng, H. Macro molecules 1997, 30, 2209 2212. (d) Pelagatti, P.; Carcelli, M.; Pelizzi, C.; Costa, M. Inorg. Chim. Acta 2003, 342, 323326.

(19) Polymerization of phenyacetylene with a rhodium complex in a mixture of monomer, toluene, and water has been reported to afford poly(phenyacetylene) particles: D'Amato, R.; Medei, L.; Venditti, I.; Russo, M. V.; Falconieri, M. Mater. Sci. Eng., C 2003, 23, 861865. 
No monomer conversion or catalyst productivity is given. Initiation of the polymerization in the aqueous phase akin to a classical emulsion polymerization is suggested, but the reaction is carried out without surfactant which would suggest a suspension-type polymerization.

(20) Deng, J.; Chen, B.; Luo, X.; Yang, W. Macromolecules 2009, 42, 933938.

(21) Krause, J. O.; Zarka, M. T.; Anders, U.; Weberskirch, R.; Nuyken, O.; Buchmeiser, M. R. Angew. Chem., Int. Ed. 2003, 42, 59655969.

(22) (a) Drent, E.; v. Broekhoven, J. A. M.; Doyle, M. J. J. Organomet. Chem. 1991, 417, 235 251. (b) Drent, E.; Budzelaar, P. H. M. Chem. Rev. 1996, 96, 66381.

(23) (a) Jiang, Z.; Sen, A. Macromolecules 1994, 27, 7215 7216. (b) Verspui, G.; Papadogianakis, G.; Sheldon, R. A. Chem. Commun. 1998, 401402. (c) Bianchini, C.; Man Lee, H.; Meli, A.; Moneti, S.; Patinec, V.; Petrucci, G.; Vizza, F. Macromolecules 1999, 32, 3859 3866. (d) Lindner, E.; Schmid, M.; Wald, J.; Queisser, J. A.; Geprags, M.; Wegner, P.; Nachtigal, C. J. Organomet. Chem. 2000, 602, 173 87. (e) Held, A.; Kolb, L.; Zuideveld, M. A.; Thomann, R.; Mecking, S.; Schmid, M.; Pietruschka, R.; Lindner, E.; Sunjuk, M.; Khanfar, M. Macromolecules 2002, 35, 33423347.

(24) (a) Drent, E.; Pello, D. H. L. Eur Pat. 576091 (Shell), 1993. (b) Li, K.; Wei, G.; Darkwa, J.; Pollack, S. K. Macromolecules 2002, 35, 45734576.

(25) LaPointe, A. M.; Brookhart, M. Organometallics 1998, 17,1530 1537.

(26) For a preliminary account cf. (a) Huber, J.; Mecking, S. Polym. Mater. Sci. Eng. 2007, 96, 306 307. (b) Reference 4.

(27) (a) Clegg, W.; Eastham, G. R.; Elsegood, M. R. J.; Heaton, B. T.; Iggo, J. A.; Tooze, R. P.; Whyman, R.; Zacchini, S. Organo metallics 2002, 21, 1832 1840. (b) Lopez-Serrano, J.; Duckett, S. B.; Aiken, S.; Almeida Lenero, K. Q.; Drent, E.; Dunne, J. P.; Konya, D.; Whitwood, A. C. J. Am. Chem. Soc. 2007, 129, 65136527.
(28) Tolman, C. A. Chem. Rev. 1977, 77, 313348.

(29) Ferreira, A. C.; Crous, R.; Bennie, L.; Meij, A. M. M.; Blann, K.; Bezuidenhoudt, B. C. B.; Young, D. A.; Green, M. J.; Roodt, A. Angew. Chem., Int. Ed. 2007, 46, 22732275.

(30) Mecking, S.; Monteil, V.; Huber, J.; Kolb, L.; Wehrmann, P. Makromol. Symp. 2006, 236, 117123.

(31) Molecular weight determination of the poly NA and poly AA was hampered by their intense color, which was anticipated to possibly result in contamination of the equipment employed.

(32) (a) Candeau, F. In Polymerization in Organized Media, Paleos, C. M., Ed.; Gordon and Breach Sci. Publ.: Philadelphia, 1992; pp 215283. (b) Antonietti, M.; Basten, R.; Lohmann, S. Macromol. Chem. Phys. 1995, 196, 441 466. (c) Pavel., F. M. J. Dispersion Sci. Technol. 2004, 25, 116

(33) Monteil, V.; Wehrmann, P.; Mecking, S. J. Am. Chem. Soc. 2005, 127,1456814569

(34) (a) Chiang, C. K.; Druy, M. A.; Gau, C. S.; Heeger, A. J.; Louis, E. J.; MacDiarmid, A. G.; Park, Y. W.; Shirakawa, H. J. Am. Chem. Soc. 1978, 100, 1013 1015. (b) Basescu, N.; Liu, Z.-X.; Moses, D.; Heeger, A. J.; Naarmann, H.; Theophilou, N. Nature 1987, 327, 403 405. (c) Heeger, A. J. Angew. Chem., Int. Ed. 2001, 40, 2591 2611.

(35) Leclerc, M.; Prud'homme, R. E. Macromolecules 1987, 20, 2153 2159.

(36) Dolhem, F.; Lièvre, C.; Demailly, G. Tetrahedron 2003, 59, 155 164.

(37) Prasad, K. R.; Nagappa; Rai, K. M. L. Synth. Commun. 1998, 28, 46054610

(38) Carr, N.; Dunne, B. J.; Mole, L.; Orpen, A. G.; Spencer, J. L. J. Chem. Soc., Dalton Trans. 1991, 863871. 